\title{
Experimental Analyses of Athabasca Bitumen Properties and Field Scale Numerical Simulation Study of Effective Parameters on SAGD Performance
}

\author{
Yaser Souraki ${ }^{1}$, Mohammad Ashrafi ${ }^{1}$, Hassan Karimaie ${ }^{1} \&$ Ole Torsaeter ${ }^{1}$ \\ ${ }^{1}$ Department of Petroleum Engineering and Applied Geophysics, Norwegian University of Science and \\ Technology - NTNU, Trondheim, Norway \\ Correspondence: Yaser Souraki, Department of Petroleum Engineering and Applied Geophysics, Norwegian \\ University of Science and Technology - NTNU, S. P. Andersensvei 15A, 7491 Trondheim, Norway. Tel: \\ 47-7359-4826. E-mail: yaser.souraki@ntnu.no
}

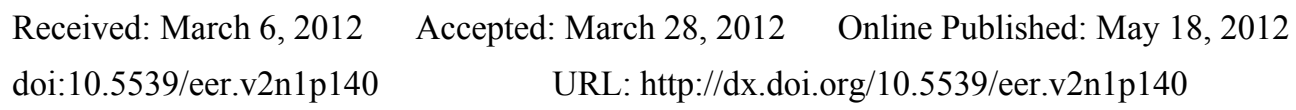

The research is financed by Statoil ASA

\begin{abstract}
Due to reduction of high quality oil resources and consequently increase of oil price around the world, new sources of energy should be find to relief the high demand of energy. Hence, countries like Venezuela, United States and particularly Canada came up with their unconventional reservoirs which contain bitumen, extra heavy oil and heavy oilas remarkable sources of energy. Exploitation of such kind of reservoirs was not beneficial in the past but in recent years due to the increase of oil price tendency to production from heavy oil reservoirs has incredibly increased.

This paper introduces experimental measurement of Athabasca heavy crude oil properties and simulation study in a field conditions. The first-hand target of the performed study isto scrutinize and evaluate the performance and capability of steam-assisted gravity drainage (SAGD) process which is the greatest applicable thermal processes in tar sand reservoirs. The results show great recovery of heavy oil and reasonable amount of cumulative steam-oil ratio (CSOR).

Sensitivity analyses have been done to realize the influence of different parameters on proficiencyof SAGD in the field. The significance of parameters such as permeability both in horizontal and vertical direction, horizontal and vertical shale barriers, injection rate, porosity, injector location, viscosity, preheating period, horizontal well length and steam quality were studied.

Higher vertical and horizontal permeability, injection rate and steam quality have positive effect on oil production while Lower porosity, absence of preheating period and higher injection rate have adverse effects on SOR. Preheating period has impact on SOR at the start of the process. In fact without preheating period the amount of SOR at the start of process is very high. Horizontal shale barrier has more negative effect on oil production than vertical shale barriers. Locating injector close to the horizontal production well has nugatory impact. The shorter the length of horizontal wells the lower the recovery of oil. This work explains the aforementioned effects in details.
\end{abstract}

Keywords: bitumen, experimental data, simulation study, SAGD process, effective parameters

\section{Introduction}

The known amounts of heavy oil reserves are 3,396 billion barrels of initial oil in place, including 30 billion barrels as futuristic additional oil. The whole discovered bitumen reserves are about 5,505 billion barrels of initial oil in place, including 993 billion barrels as futuristic additional oil (USGS, 2007). Venezuela and North-America especially Canada have the greatest accumulation amounts of bitumen and heavy oil reserves in their carbonate and sandstone reservoirs (Nasr \& Ayodele, 2006). Cold Lake, Athabasca and Peace River which possess more than $60 \%$ of total natural bitumen resources are located in Alberta State of Canada (Attanasi \& Meyer, 2007). 
There are different methods for producing from unconventional reservoirs based on the principle of lowering bitumen and heavy oil intrinsic viscosity. This reduction may be performed using injection of steam inside the reservoir (increasing the temperature of reservoir contents) or by dissolution of special solvents into the bitumen (solvent injection) or by use of benefits of both of them. Hot water injection, in-situ combustion,steam-assisted gravity drainage (SAGD) and cyclic steam stimulation (CSS)are examples of thermal processes and vapor extraction (VAPEX) (Butler, 1991a) is an example of solvent injection method. Among the thermal processes, SAGD is the most efficient and promising method which was pioneered and developed by Butler (Butler, 1981). This method benefits from advantage of horizontal well technology which has a greater contact area to the reservoir. In this method two horizontal wellsare drilled with vertical spacing about $5 \mathrm{~m}$ at the point with greatest height from the top of the reservoir to have a greater recovery. The bottom well is considered as producer while the upper one is injector. Heat will be transferred into the reservoir by injection of steam via injector. The formation and its contents will be heated up to the steam temperature gradually due to the high heat capacity of steam. Bitumen viscosity decreases by increasing temperaturewithin the steam contacted area and forms a reverse triangle zone which is known as steam chamber area.This aforementioned region advances upward to reach to the top of the reservoir and then to the surrounding area (Butler, 1991b). Gravity drainage is the principal mechanism of recovery process that helps to recover melted, mobile bitumentogether withthe amounts of steam which are condensed due to contact with cold oilat the boundary of steam chambervia horizontal production well. The most important economic factor of SAGD is the amount of CSOR, because steam generation is a very expensive process and need its special facilities. The amount of required steam is measured based on cold water equivalents to recover each unit of produced bitumen. The economic range of CSOR in the field condition is in the range of $2-10 \mathrm{~m}^{3} / \mathrm{m}^{3}$ (Gates \& Chakrabarty, 2006). SAGD recovery method has been tested by several experimental works and afterwards it has been implemented in some pilot cases.Nowadays, Athabasca and Cold Lake regions in Canada are using SAGD recovery process as a commercial method.

Here, numerical simulation on SAGD process in field conditionshas been performed to peruse the effect of different parameters. The resultswere compared based on the CSORand recovery factor. Some experimental work on Athabasca bitumen properties were also presented here.

\section{Experimental Work}

In order to have better insight and understanding about our bitumen sample, different laboratory works have been done to obtain some PVT data which can be used for further experimental and simulation works. These useful and valuable PVT data will be presented in this paper (for details refer to CSUG/SPE 147064). The measured PVT data are as follow:

\subsection{Compositional Analysis and Molar Mass}

Gas Chromatography (GC) technique has been used to specify the compositions of Athabasca bitumen. In general, it is feasible to distinguish individual n-alkanes by noticeable crests in chromatographs of light crude oils. An n-alkane standard giving clearance recognition of the crests in chromatographs is used to calibrate the GC. The retention time of $n$-alkane was applied as a parameter to divide the bitumen fraction into several groups. Each individual group was measured in terms of $\mu \mathrm{g} / \mathrm{mg}$ oil. Table 1 shows the results of analyses for Athabasca oil compositions. The compositions are in combinedfractions from $\mathrm{C} 11+\mathrm{C} 12$ to $\mathrm{C} 37+\mathrm{C} 38$. It was not feasible to distinguish the fractions heavier than $\mathrm{C} 38$; hence, heavier fractions were lumped as a $\mathrm{C} 39+$. The second column in Table 1 presents the concentration amount of each pseudo-component in according to weight percent. The Katz-Firoozabadi approach (1978) was applied to drive molar concentration of each group. In order to measure molar mass of Athabasca bitumen, cryoscopy technique was performed using a Roebling Kryometer. In this method, first certain amount of crude oil is weighted and then this amount of oil is added to benzene. Afterwards, depression of the solution freezing point is quantified and compared relative to the freezing point of pure benzene to identify the molar mass of sample bitumen. Based on this technique the molar mass of Athabasca bitumen was figured out to $534 \pm 2 \mathrm{~g} / \mathrm{mol}$.

\subsection{Density}

Oil density measurement is necessary in order to evaluate and characterize the crude oil. Anton Paar apparatus was used to determine the density of Athabasca bitumen at high temperature and high pressure conditions. The pure water and nitrogen were used to calibrate the apparatus at objective temperatures which oil density has to be obtained. Bitumen is immobile due to its intrinsic high viscosity at low temperatures (at room temperature greater than $5 \times 10^{5} \mathrm{cP}$ ). Therefore the injected oil temperature was raised to $120{ }^{\circ} \mathrm{C}$ and the Anton Paar apparatus was also heated up to $120^{\circ} \mathrm{C}$ in order to avoid stocking of bitumen during density measurements. Then it was cooled down to standard temperature, $60^{\circ} \mathrm{F}\left(15.56^{\circ} \mathrm{C}\right)$. The oil density was obtained at several pressures from 5 
to 25 bara.

Table 1. Compositional analysis of Athabasca oil

\begin{tabular}{ccccc}
\hline Pseudo-component & Amount (Weight \%) & Amount $(\mathrm{mol} \%)$ & Molar mass $^{\mathrm{a}}(\mathrm{g} / \mathrm{mol})$ & Density $^{\mathrm{a}}\left(\mathrm{g} / \mathrm{cm}^{3}\right)$ \\
\hline $\mathrm{C}_{10}$ & 0.211 & 0.842 & 134.0 & 0.7780 \\
$\mathrm{C}_{11}+\mathrm{C}_{12}$ & 0.948 & 3.286 & 154.0 & 0.7945 \\
$\mathrm{C}_{13}+\mathrm{C}_{14}$ & 1.976 & 5.782 & 182.5 & 0.8165 \\
$\mathrm{C}_{15}+\mathrm{C}_{16}$ & 3.006 & 7.501 & 214.0 & 0.8355 \\
$\mathrm{C}_{17}+\mathrm{C}_{18}$ & 3.731 & 8.166 & 244.0 & 0.8495 \\
$\mathrm{C}_{19}+\mathrm{C}_{20}$ & 4.068 & 8.075 & 269.0 & 0.8595 \\
$\mathrm{C}_{21}+\mathrm{C}_{22}$ & 3.959 & 7.094 & 298.0 & 0.8695 \\
$\mathrm{C}_{23}+\mathrm{C}_{24}$ & 3.759 & 6.186 & 324.5 & 0.8790 \\
$\mathrm{C}_{25}+\mathrm{C}_{26}$ & 3.594 & 5.453 & 352.0 & 0.8870 \\
$\mathrm{C}_{27}+\mathrm{C}_{28}$ & 3.602 & 5.048 & 381.0 & 0.8945 \\
$\mathrm{C}_{29}+\mathrm{C}_{30}$ & 3.437 & 4.487 & 409.0 & 0.9005 \\
$\mathrm{C}_{31}+\mathrm{C}_{32}$ & 3.265 & 3.989 & 437.0 & 0.9075 \\
$\mathrm{C}_{33}+\mathrm{C}_{34}$ & 2.577 & 2.959 & 465.0 & 0.9130 \\
$\mathrm{C}_{35}+\mathrm{C}_{36}$ & 2.599 & 2.815 & 493.0 & 0.9180 \\
$\mathrm{C}_{37}+\mathrm{C}_{38}$ & 2.309 & 2.366 & 521.0 & 0.9230 \\
$\mathrm{C}_{39+}$ & $56.960^{\mathrm{b}}$ & 25.950 & $11.72 .1^{\mathrm{c}}$ & $1.1474^{\mathrm{d}}$ \\
Total/Average & 100.000 & 100.000 & 534.0 & 1.0129 \\
\hline
\end{tabular}

a

Molar mass and density for pseudo-components up to $\mathrm{C}_{38}$ are according to the Katz-Firoozabadi generalized properties (1978). Property values for combined fractions $C_{11}+C_{12}$ to $C_{37}+C_{38}$ represent averages.

b The $\mathrm{C}_{39+}$ fraction consists of characterized material $(9.133 \mathrm{wt} \%)$ plus material unaccounted for in the analysis (47.827 wt \%).

c Calculated using measured molar mass $534 \mathrm{~g} / \mathrm{mol}$.

d Calculated using measured oil density $1.0129 \mathrm{~g} / \mathrm{cm}^{3}$ at standard conditions ( $1 \mathrm{~atm}, 60{ }^{\circ} \mathrm{F}$ ).

Although calibration of apparatus was performed at 20 bara but allowed precise measurement of oil density at other pressures within the range of 5-25 bara. It was validated by measuring water density at multifarious pressures. To have reliable pressure data it is necessary to measure the density at high pressure conditions because at lower pressures near to atmospheric conditions it is not possible to obtain credible pressure readings due to the bitumen's high intrinsic viscosity. The crude bitumen density was also obtained at different elevated temperatures between $120^{\circ} \mathrm{C}$ to $180^{\circ} \mathrm{C}$ in a $20^{\circ} \mathrm{C}$ steps and finally $190{ }^{\circ} \mathrm{C}$. Table 2 gives the obtained density values at standard temperature for various pressures while Table 3 exhibits these values at constant pressure of 20 bara which was calibration pressure for different temperatures. Figure 1 shows pressure sensitivity of Athabasca crude density at measured pressures versus temperature. The linearity of data is a great outstanding from Figure 1, Tables 2 and 3 . The resulted equation 1 can be suggested from that linearity which representsthe correlation between pressure $(\mathrm{p})$, density $\left(\rho_{\mathrm{oil}}\right)$ and temperature $(\mathrm{t})$. This equation is valid in the range of measured pressures and temperatures at experimental conditions.

$$
\rho_{\text {oil }}(t, p)=\rho_{\text {oil }}\left(t, p_{\text {ref }}\right)+\left(\frac{\Delta \rho_{\text {oil }}}{\Delta p}\right)_{t}\left(p-p_{\text {ref }}\right)=\left[A\left(t-t_{\text {ref }}\right)+B\right]+\left[C\left(t a-t_{\text {ref }}\right)+D\right]\left(p-p_{\text {ref }}\right)
$$

Where, $p_{\text {ref }}$ is 20 Bara as a calibration (reference) pressure and $t_{\text {ref }}$ is $160{ }^{\circ} \mathrm{C}$ and considered as a reference temperature. Considering the units of bara, ${ }^{\circ} \mathrm{C}$ and $\mathrm{g} / \mathrm{cm}^{3}$ for pressure, temperature and densityrespectively, the constants A, B, C and D can be defined as:

$$
\begin{aligned}
& \left.\mathrm{A}=-(6.32 \pm 0.04) \cdot 10^{-4} \mathrm{~g} / \mathrm{cm}^{3} /{ }^{\circ} \mathrm{C}\right], \mathrm{B}=0.9228 \pm 0.0001\left[\mathrm{~g} / \mathrm{cm}^{3}\right] \\
& \mathrm{C}=-(4.04 \pm 0.03) \cdot 10^{-7}\left[1 / \mathrm{bar}{ }^{\circ} \mathrm{C}\right], \mathrm{D}=-(9.88 \pm 0.01) \cdot 10^{-5}[1 / \mathrm{bar}]
\end{aligned}
$$


Now it is feasible to obtain the bitumen density for other pressures and temperatures. Clearly, extrapolation of equation 1 gives the density value of $1.0133 \mathrm{~g} / \mathrm{cm}^{3}$ for a temperature of $15.56{ }^{\circ} \mathrm{C}\left(60{ }^{\circ} \mathrm{F}\right)$ and atmospheric pressure as a standard condition. This result shows that Athabasca bitumen is slightly heavier than water at standard conditions.

Table 2. Athabasca oil density at constant temperature $15.56{ }^{\circ} \mathrm{C}$

\begin{tabular}{ll}
\hline Pressure(bara) & Density $\left(\mathrm{g} / \mathrm{cm}^{3}\right)$ \\
\hline 5.00 & 1.01330 \\
10.00 & 1.01358 \\
15.00 & 1.01385 \\
20.00 & 1.01411 \\
25.00 & 1.01439 \\
\hline
\end{tabular}

Table 3. Athabasca oil density at constant pressure 20 bara

\begin{tabular}{ll}
\hline Temperature $\left({ }^{\circ} \mathrm{C}\right)$ & Density $\left(\mathrm{g} / \mathrm{cm}^{3}\right)$ \\
\hline 120.00 & 0.94801 \\
140.03 & 0.93532 \\
160.00 & 0.92318 \\
180.00 & 0.90992 \\
195.00 & 0.90073 \\
\hline
\end{tabular}

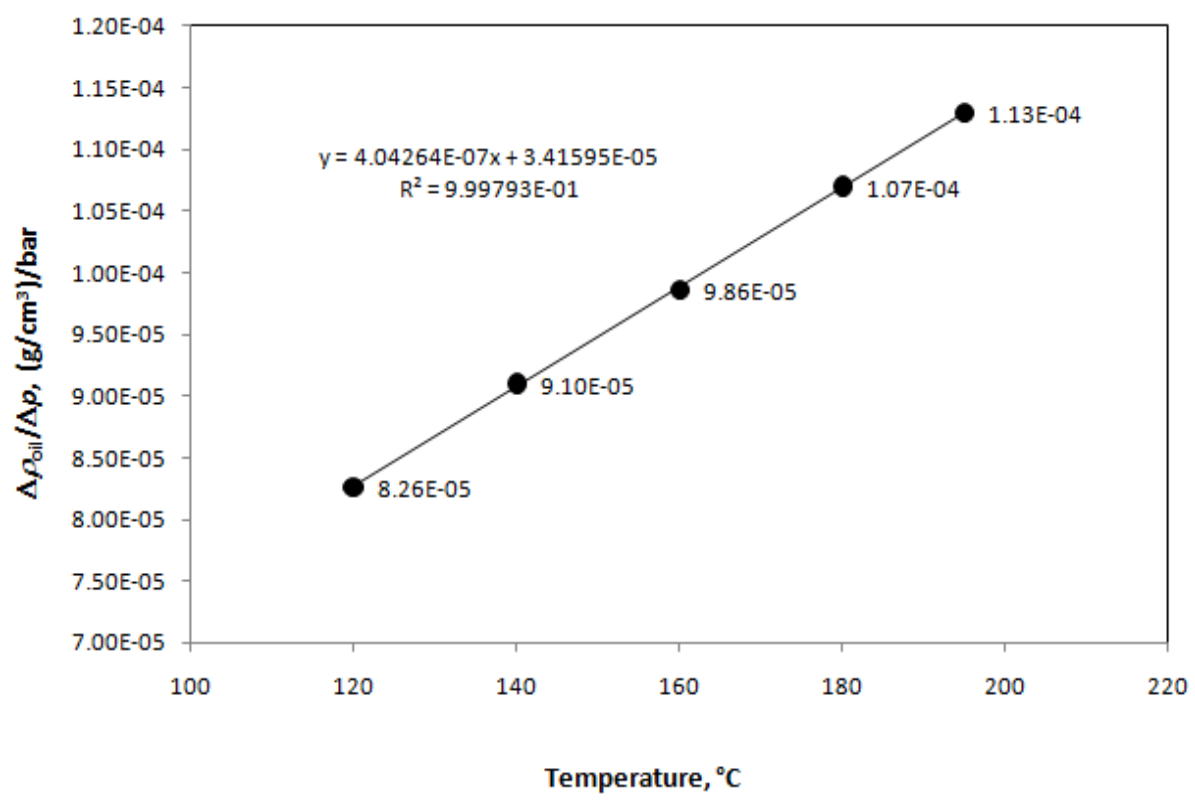

Figure 1. Pressure sensitivity of Athabasca oil density in the range 5-25 bara versus temperature

\subsection{Viscosity}

The intrinsic resistance of a fluid to deformation is called viscosity. Principally shear stress $(\tau)$ and shear rate $(\gamma)$ are proportional to each other by viscosity. Equation 2 represents the relationship of these three parameters:

$$
\tau=\mu \gamma
$$

The main assumption of the above equation is that there is no slippage of fluid at the plate surface. In the SI unit system, viscosity is expressed in Pa.s but in practical cases especially in the oil field conditions it is expressed in terms of centipoise, cP, which is corresponding to 10-3 Pa.s. Generally fluids are classified into two different 
classes based on the viscosity performance. Gases and water are classified as Newtonian fluids. Viscosity function of these fluids is not dependent to shear rate and shear stress; hence, there is a linear relationship between shear stress and shear rate (Equation 2) for Newtonian fluids. The fluids of second category are called non-Newtonian fluids. There is no proportionality between shear rate and shear stress of this type of fluids. Mostly complex mixtures such as polymer solutions, toothpastes, ketchup and blood are examples of this category.

Temperature, pressure and molecular weight are the most important factors which are affecting the viscosity of fluids. Among these factors, temperature is more effective. In fact, viscosity is strongly sensitive and dependent to the temperature than pressure unless very high pressures have been achieved. Generally at constant temperature, increase in pressure will increase the viscosity of liquids but in many practical instances the pressure dependency of liquids viscosity can be ignored. Increase in temperature will result in reduction of viscosity of liquids while the viscosity of gases has an inverse trend with increase in temperature. The heavier the molecular weight of liquid, the higher the viscosity of the liquid. The Bitumen crude oil has large viscosity, usually in a magnitude of millions of $\mathrm{cP}$ at reservoir conditions because bitumen contains asphaltenes which are very complex molecules with high carbon to hydrogen ratios characteristic. There are different approaches to measure viscosity of fluids and each approach has its specific viscometer such as: capillary viscometer, falling ball viscometer and rotational viscometer. The first two viscometers are applied to measure the viscosity of lighter oils but the last one is usually applied to obtain the viscosity of heavier crude oils like bitumen.

Here, using Brookfield LVDV-II+Pro rotational viscometer,the viscosity of Athabasca crude oil was obtained at different temperatures from $20{ }^{\circ} \mathrm{C}$ which was lab temperature to $300{ }^{\circ} \mathrm{C}$ which was the temperature limit of viscometer. Mehrotra and Svercek (1986) performed several measurements of bitumen viscosity versus temperature. The comparison of our measured viscosity data and their experimental data is presented in Figure 2.

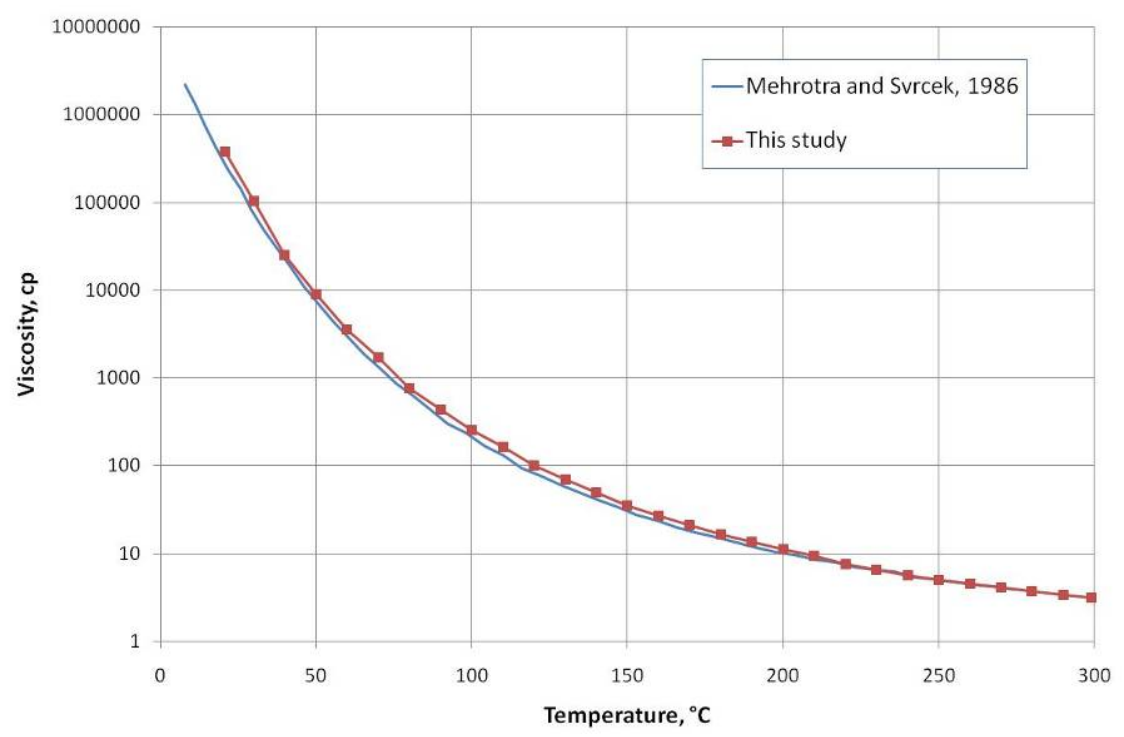

Figure 2. Viscosity of Athabasca bitumen versus temperature

\subsection{IFT Measurement}

The liquid surface has a leaning to behave like a stretched elastic membrane. This tendency is called surface tension. Minimizing the surface area is a natural tendency of liquids and this tendency leads to the spherical shape of liquid drop. There is a difference between energy of molecules at liquid surface and molecules in the interior of a liquid. Molecules inside the liquid have less energy than molecules at liquid surface. So the required works have to be done in order to bring the interior molecules to the surface.This necessary work is a liquid surface tension ( $\sigma$ sigma) which is expressed in $\mathrm{N} / \mathrm{m}$ in SI unit system while in practical purposes it is usually expressed in terms of dynes per centimeter which is equal to the $0.001 \mathrm{~N} / \mathrm{m}$.

There are several methods to obtain interfacial tension between two liquids. Some examples of these methods are: bubble pressure method, Wilhelmy plate method, ring method, sessile drop method, capillary rise method, drop 
weight method, pendant drop method, spinning drop method and etc.

To measure the IFT between steam and Athabasca bitumen, pendant drop method were applied in two measurement series A and B. First, sample A was taken to obtain the IFT values at several temperatures in steps of $20^{\circ} \mathrm{C}$ from $160{ }^{\circ} \mathrm{C}$ to $220^{\circ} \mathrm{C}$. Due to some uncertainty about sample A integrity, another sample (sample B) was taken to repeat the experiment at temperatures range from $120^{\circ} \mathrm{C}$ to $200{ }^{\circ} \mathrm{C}$ in intervals of $20^{\circ} \mathrm{C}$. The result drops are in the following specified by Series/Temperature/Number (e.g. B/140 ${ }^{\circ} \mathrm{C} / \mathrm{H} 2$ ). The ratio between IFT and the density difference between drop and surrounding medium, (IFT/ $\Delta \rho)$, was a basic quantity which obtained by pendant drop shape method.

Utilizing an in-house software and calculated oil density and steam density values by equation (1) and Wagner-Pruss (2002) equation of state respectively, the IFT quantities were obtained from the initial data by pendant drop method. There is an assumption that equation (1) can be extrapolated to $220{ }^{\circ} \mathrm{C}$. Another assumption is that equilibration of oil and steam did not alter either oil or steam densities considerably from the pure-substance value.Table 4 and Figure 3 illustrate the measured average IFT values at the mentioned experimental temperatures. The measured interfacial tension had a subtractive trend from $25 \mathrm{mN} / \mathrm{m}$ to $18 \mathrm{mN} / \mathrm{m}$ with increase in experimental temperature.

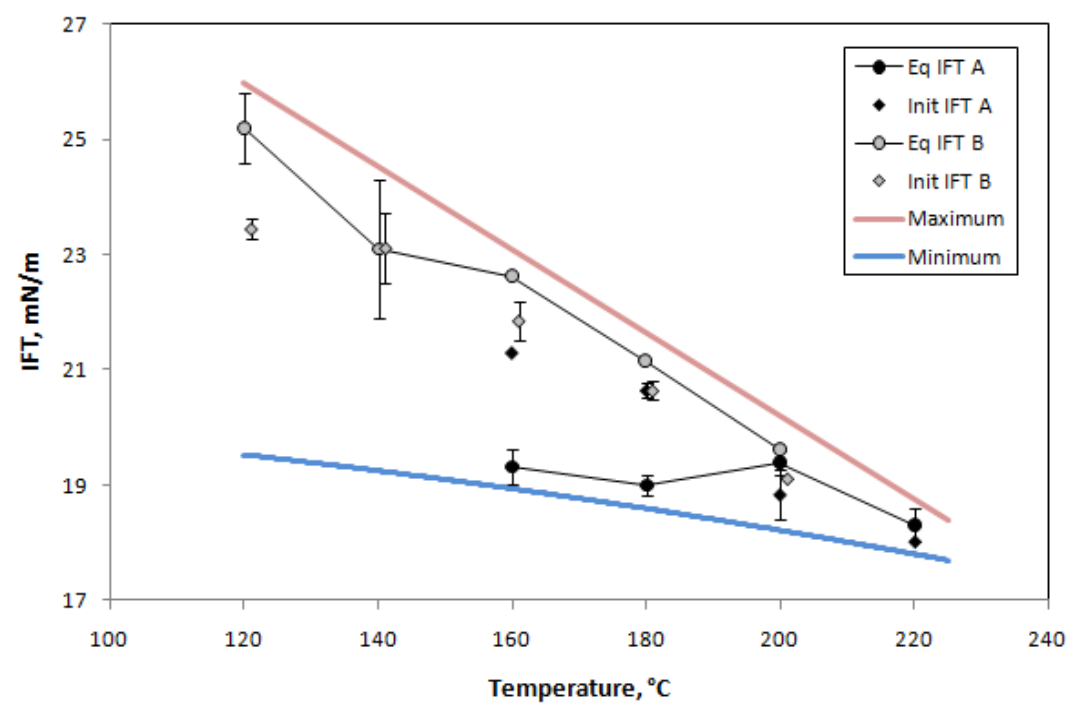

Figure 3. Initial and equilibrium interfacial between Athabasca oil and steam (some data points have been shifted slightly along the temperatures axis for clarity)

Table 4. Average initial and equilibrium interfacial tension values in Series A and B

\begin{tabular}{ccccccc}
\hline Series & $\begin{array}{c}\text { Average temperature } \\
\left({ }^{\circ} \mathrm{C}\right)\end{array}$ & $\begin{array}{c}\text { Average pressure } \\
(\text { bara })\end{array}$ & $\begin{array}{c}\text { Initial IFT } \\
(\mathrm{mN} / \mathrm{m})\end{array}$ & $\begin{array}{c}\mathrm{SD}^{\mathrm{a}} \text { initial IFT } \\
(\mathrm{mN} / \mathrm{m})\end{array}$ & $\begin{array}{c}\text { Equilibrium IFT } \\
(\mathrm{mN} / \mathrm{m})\end{array}$ & $\begin{array}{c}\mathrm{SD}^{\mathrm{a}} \text { Eq. IFT } \\
(\mathrm{mN} / \mathrm{m})\end{array}$ \\
\hline $\mathrm{A}$ & 159.95 & 4.29 & 23.17 & 0.08 & 19.31 & 0.31 \\
$\mathrm{~A}$ & 180.03 & 8.56 & 22.82 & 0.16 & 19.00 & 0.18 \\
$\mathrm{~A}$ & 199.95 & 13.71 & 21.17 & 0.51 & 19.39 & 0.21 \\
$\mathrm{~A}$ & 220.11 & 20.32 & 20.60 & 0.11 & 18.30 & 0.28 \\
$\mathrm{~B}$ & 120.03 & 1.86 & 24.80 & 0.17 & 25.19 & 0.60 \\
$\mathrm{~B}$ & 140.08 & 3.01 & 24.80 & 0.66 & 23.10 & 1.21 \\
$\mathrm{~B}$ & 159.94 & 5.51 & 23.79 & 0.38 & 22.63 & 0.14 \\
$\mathrm{~B}$ & 179.88 & 8.22 & 22.82 & 0.19 & 21.16 & 0.11 \\
$\mathrm{~B}$ & 200.02 & 14.11 & 21.48 & 0.09 & 19.62 & 0.02 \\
\hline
\end{tabular}

a: Standard deviation of individual measurements (not for the mean) 


\section{Simulation Results}

Several numerical simulation studies were accomplished in a field scale using aforementioned experimental data. Steam-Assisted Gravity Drainage (SAGD), one of the most promising recovery methods which are dominantly applied in heavy oil and bitumen reservoirs was simulated.

\subsection{Model description}

A 2-D Cartesian model containing Athabasca Bitumen was built to be a representative of Athabasca reservoir. Figure 4 represents constructed grid system of $101 \times 1 \times 15$ which was used to simulate the reservoir. Table 5 shows the model characteristics. The reservoir specifications and properties of fluids are presented in Table 5 . Relative permeability data are shown in Figure 5. Horizontal production well is drilled at the bottom of the reservoir and about $5 \mathrm{~m}$ above the production well, another horizontal well which is considered as injection well is placed. Table 6 summarized steam injection conditions.
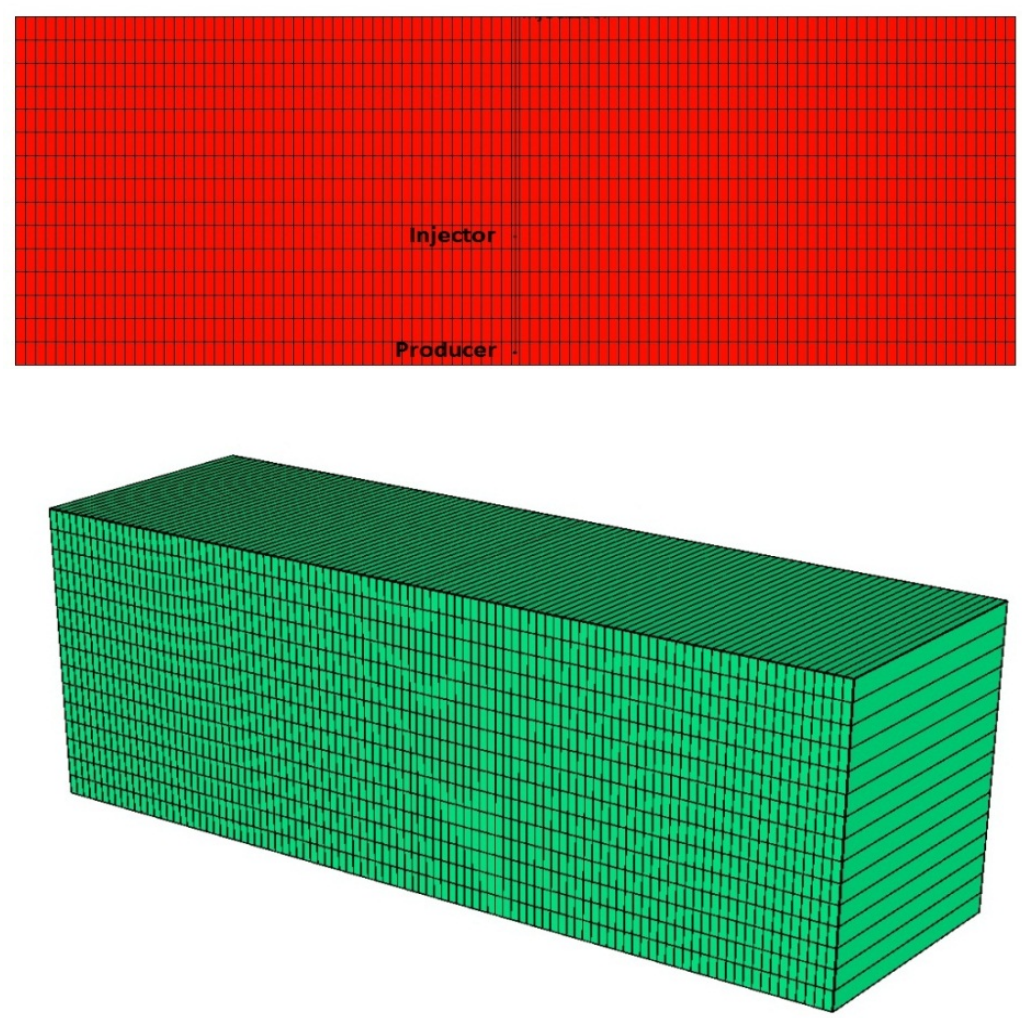

Figure 4. Illustration of the simulation model
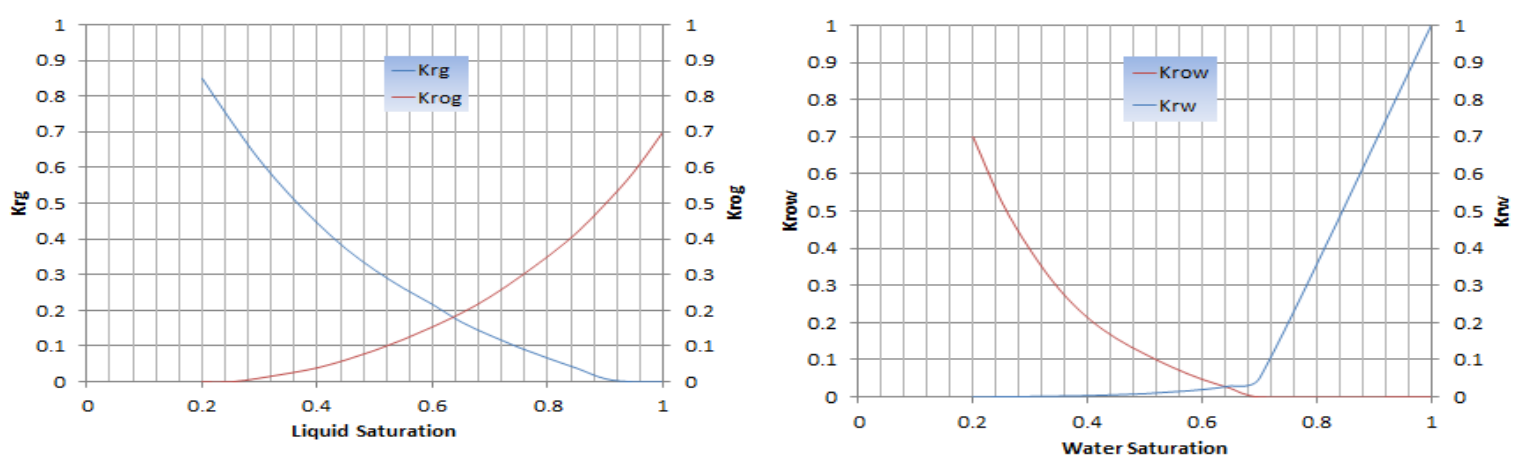

Figure 5. Sketch of the relative permeability data (Chen 2009) 
Table 5. Numerical simulation model characteristics

\begin{tabular}{|c|c|c|c|}
\hline \multicolumn{2}{|c|}{ Model Definitions and Reservoir Characterisation } & \multicolumn{2}{|l|}{ Rock and Fluid properties } \\
\hline Cartesian model & & Rock thermal conductivity(Btu/(ft*day*F)) & 106 \\
\hline Homogeneous & & Rock heat capacity $\left(\mathrm{Btu} /\left(\mathrm{ft}^{3} * \mathrm{~F}\right)\right)$ & 35 \\
\hline Length of model & $101.4 \mathrm{~m}$ & Density of bitumen $\left(\mathrm{Kg} / \mathrm{m}^{3}\right)$ & 1013.3 \\
\hline Width & $30.28 \mathrm{~m}$ & Thermal expansion coefficientof bitumen $\left(1 /{ }^{\circ} \mathrm{C}\right)$ & $7.2 \mathrm{E}-4$ \\
\hline Height (thickness) & $13.72 \mathrm{~m}$ & Molecular weight (Kg/Kgmole) & 534 \\
\hline Initial oil in place & $14443.5 \mathrm{Sm}^{3}$ & Rock compressibility (1/psi) & $5 \mathrm{E}-4$ \\
\hline Porosity & $38 \%$ & & \\
\hline Horizontal permeability & $7000 \mathrm{mD}$ & & \\
\hline Vertical permeability & $2100 \mathrm{mD}$ & & \\
\hline Initial temperature & $10^{\circ} \mathrm{C}$ & & \\
\hline Initial pressure & $2068 \mathrm{kPa}$ & & \\
\hline Swi & 0.20 & & \\
\hline Soi & 0.80 & & \\
\hline No. of grid blocks & $101 \times 1 \times 15$ & & \\
\hline
\end{tabular}

Table 6. Steam injection conditions

\begin{tabular}{ll}
\hline Steam quality & $90 \%$ \\
Steam injection rate(STB/DAY) & 200 \\
Steam injection temperature $\left({ }^{\circ} \mathrm{C}\right)$ & 215.5 \\
Preheating period(using heater to warm the area between twohorizontal wells @ $\left.260^{\circ} \mathrm{C}\right)$ & 100 days \\
\hline
\end{tabular}

\section{Results and Discussion}

\subsection{Base Case}

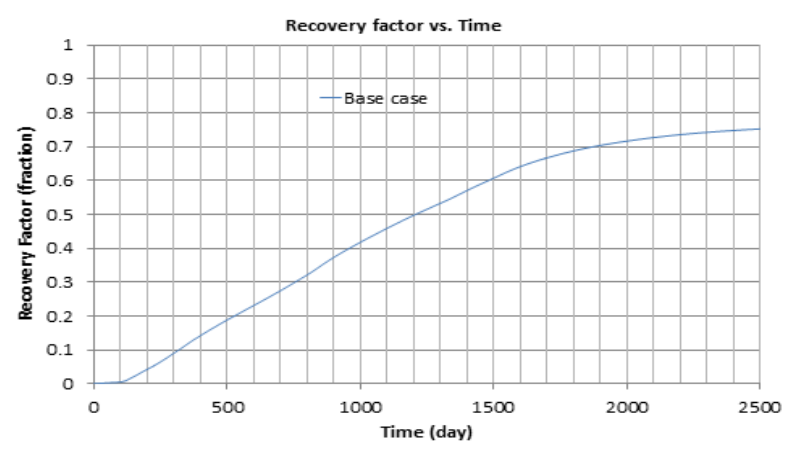

a) Recoveryfactorvs. Time

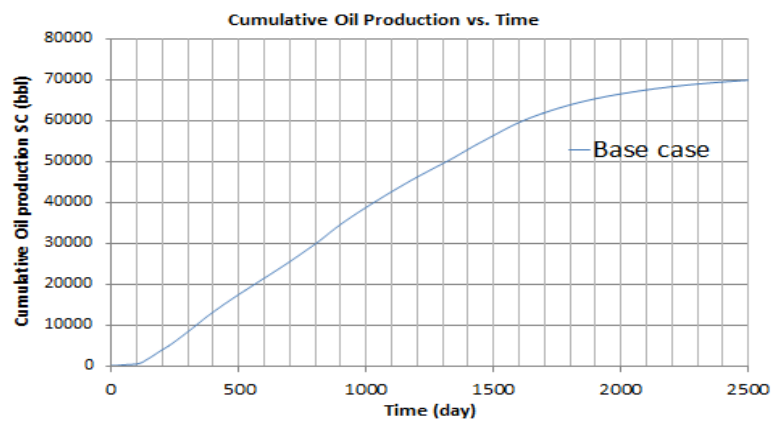

c) Cumulativeoilproductionvs. Time

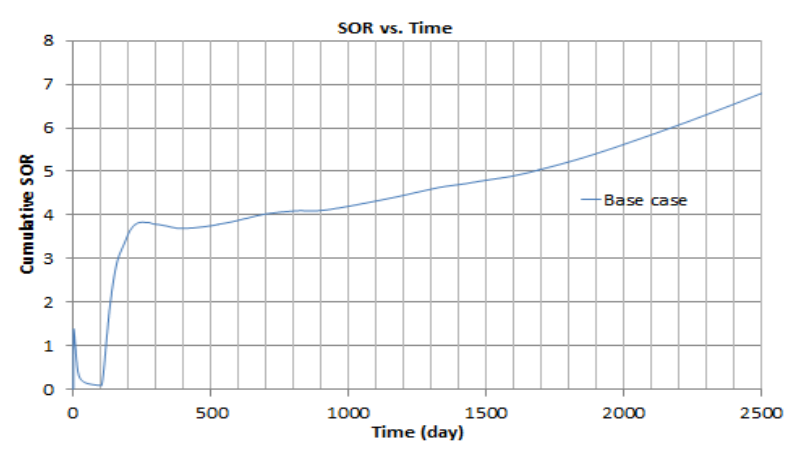

b) CSOR vs. Time

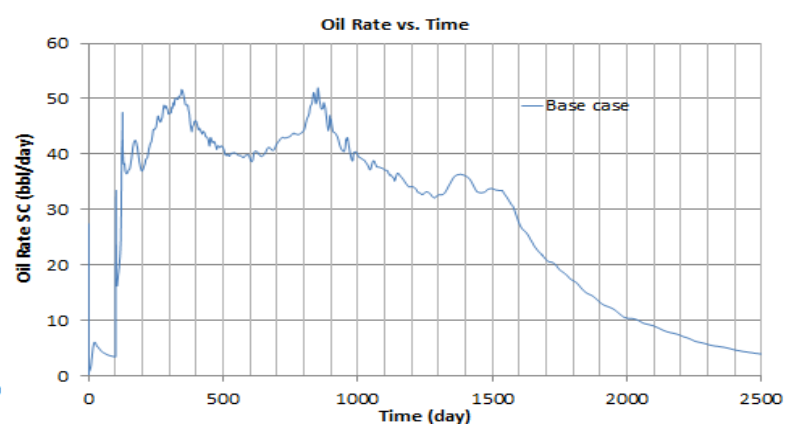

d) Oil rate vs. Time

Figure 6. Base case simulation results 
Results show that Steam-Assisted Gravity Drainage (SAGD) process was efficient and has a reasonable recovery factor and economical steam-oil ratio (SOR). These results are related to the parameters which were mentioned above so these are called base case results. Cumulative production oil was around $10.883 \mathrm{~m}^{3}$ (recovery factor of 0.75 ) and maximum amount of CSOR was less than 6.8 . The production was started approximately 70 days after start of the process. Figure 6 clearly represents moreinformation about the process.

Temperature profile vs. Time is shown in Figure 7. As it can be seen, first steam propagates towards the top of the reservoir, so there is a counter current flow of steam and condensate in this step and may cause some emulsion formation. While steam chamber reaches to the top then moves towards the sides of reservoir and transfers heat to the rest of the reservoir. In this step, steam sweeps much better and increases the amount of produced oil.

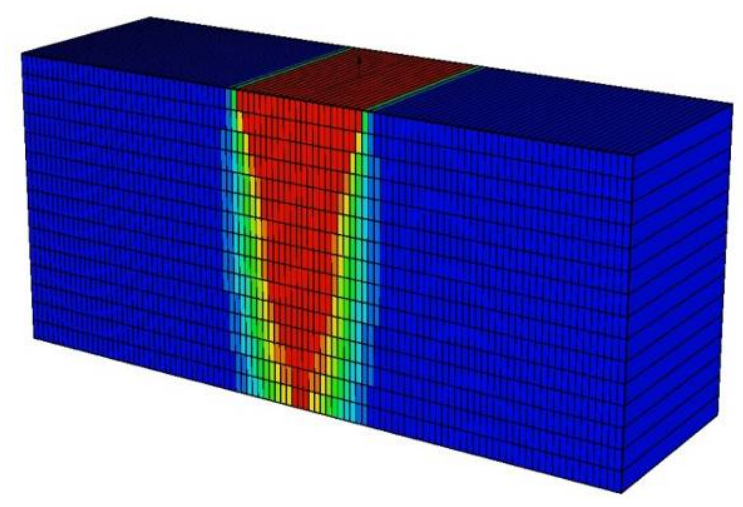

a) after 200 days

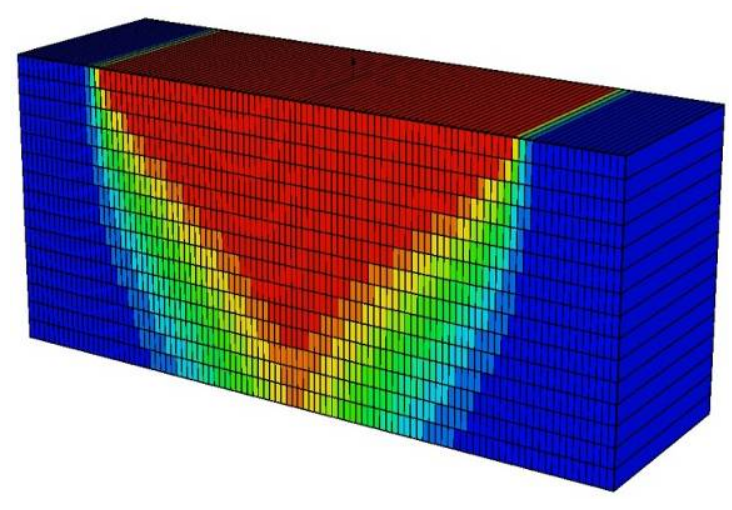

c) after500days

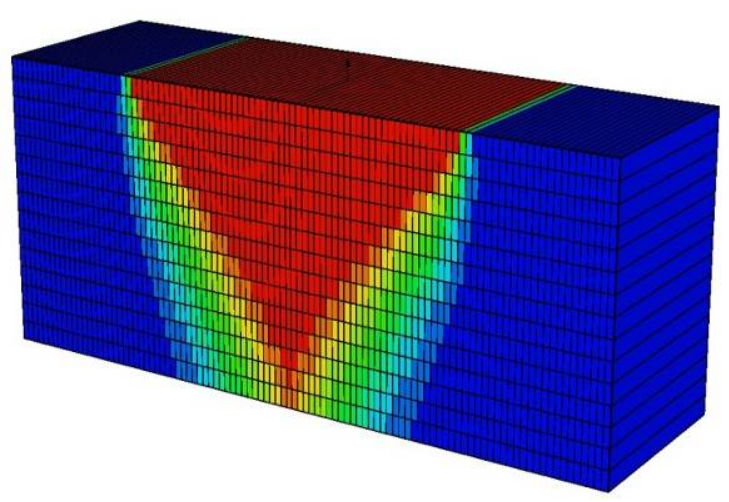

b) after 400 days

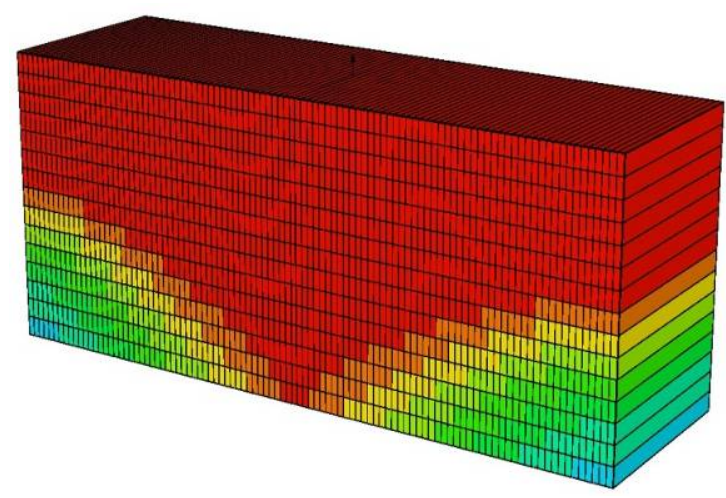

d) after 1000 days

Figure 7. Illustration of temperature profile vs. time

\subsection{Sensitivity Analyses}

In order to evaluate the effects of different parameters on SAGD process performance some sensitivity analyses were performed. The results will be presented here:

\subsubsection{Effect of Viscosity}

Two different oil viscosity data (Athabasca bitumen and cold lake heavy oil) were applied to study the effect of viscosity (Figure 8). Figure 9b represents that higher viscosity will lead to higher SOR at earlier times (while Steam chamber growing to the top) but afterwards both of them are identical because the steam chamber has propagated from top towards the sides of reservoir and made a better sweep due to co-current flow of steam and condensates. 


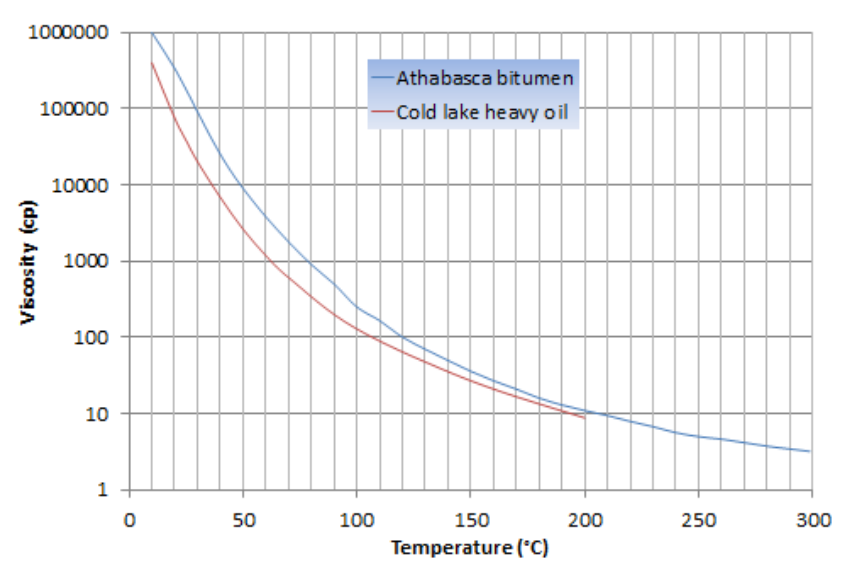

Figure 8. Illustration of two different viscosity data

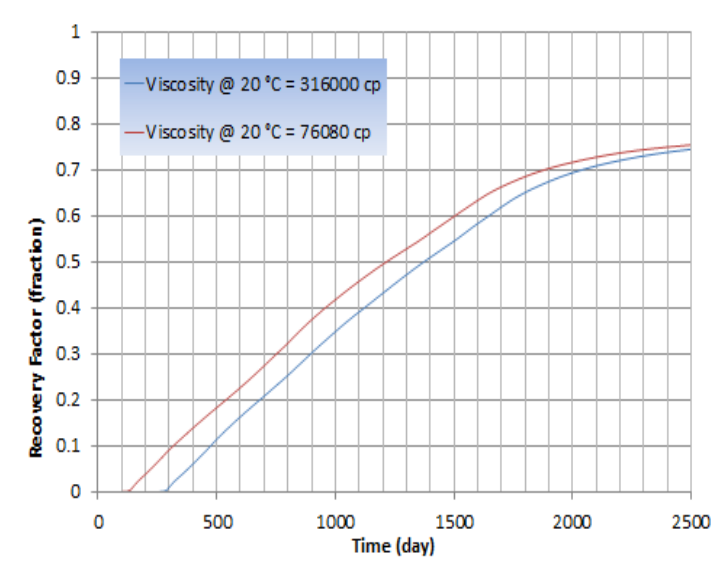

a) Recovery factor vs. Time

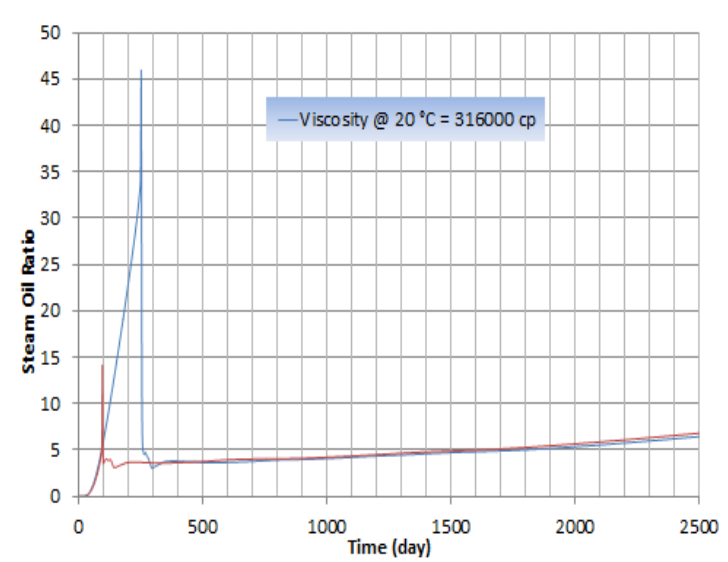

b) CSOR vs. Time

Figure 9. Impact of viscosity on SAGD process

\subsubsection{Effect of Grid Refinement}

Grid refinement was done along the horizontal wells length to compare the basic 2-D model and the obtained 3-D model. Results represent that no major difference exists between these two models although 3-D model has more precise data than 2-D model (Figure 10). There was a limit for the number of grids in our software so it was not possible to increase the amount of grids more than 10000 . Higher amount of grid blocks can diminish the numerical dispersion which is one of the basic errors for any simulation study.

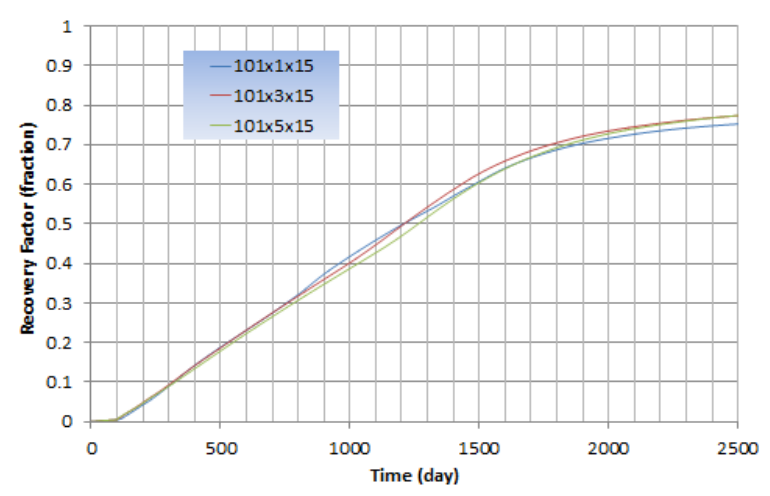

a) Recovery factor vs. Time

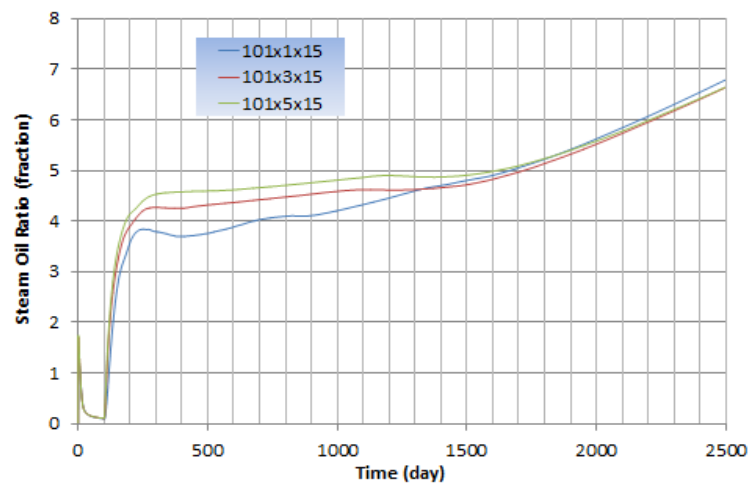

b) CSOR vs. Time

Figure 10. Illustration of grid refinement effect 


\subsubsection{Effect of Different Horizontal Permeability}

Permeability is one of the most important parameters which its accurate value is vital for reservoir evaluation. Three schemes were applied to investigate the effect of reduction in permeability of the reservoir: 1- reduction in horizontal permeability, 2- reduction in vertical permeability, 3- reduction in permeability both in horizontal and vertical directions. Changing permeability is incredibly affecting the proficiency of the SAGD process so that in the worst case (case 3 ) recovery factor (RF) reduced to the one-third of the base case while SOR increased four times. Also ten times reduction in horizontal permeability reduced the RF to half and doubled the SOR. Figures 11,12 and 13 demonstrate related results.

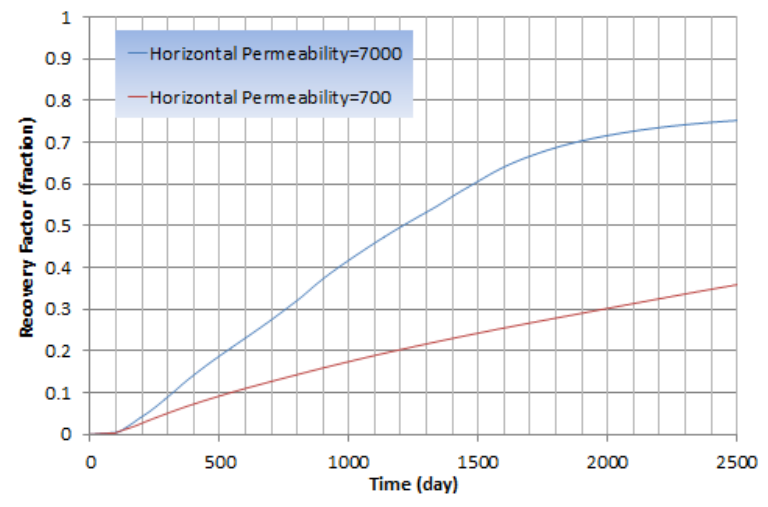

a) Recoveryfactorvs.Time

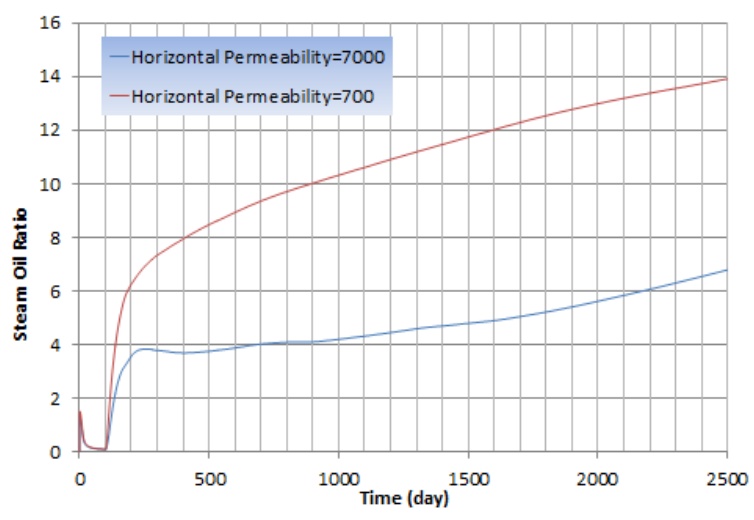

b) CSOR vs. Time

Figure 11. Illustration of horizontal permeability reduction effect

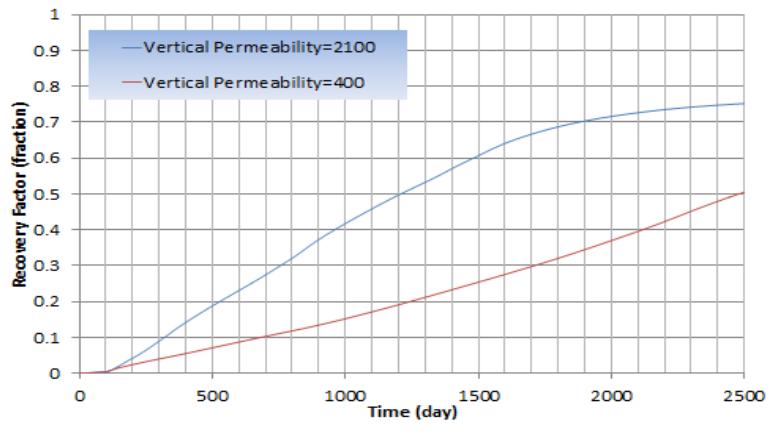

a) Recoveryfactorvs. Time

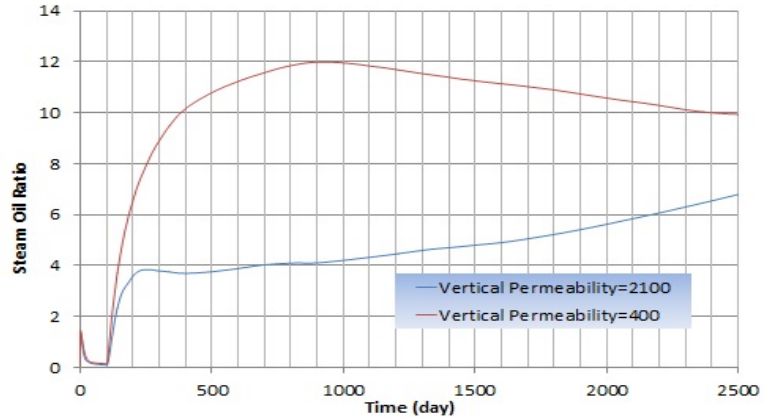

b) CSOR vs. Time

Figure 12. Illustration of vertical permeability reduction effect

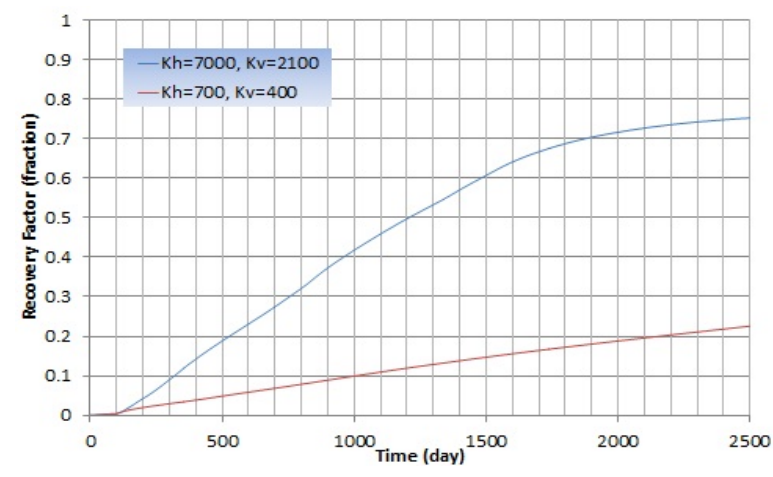

a) Recovery factor vs. Time

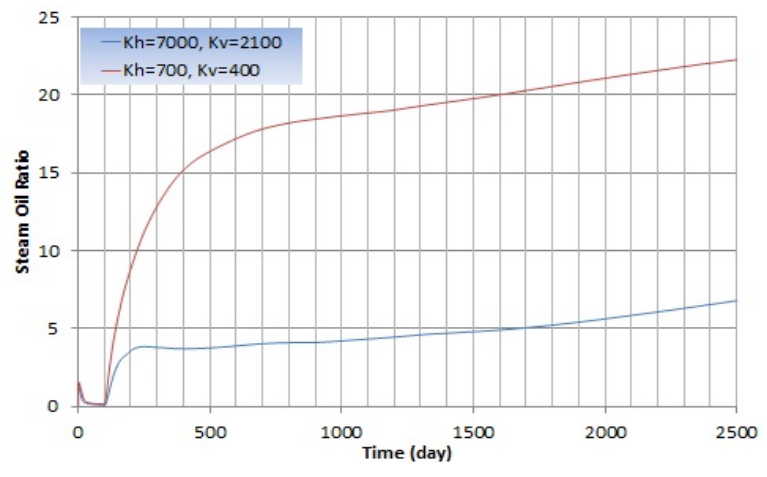

b) CSOR vs. Time

Figure 13. Illustration of effect of reduction in permeability both in horizontal and vertical directions 


\subsubsection{Effect of Porosity}

Porosity is another important parameter that should be considered in reservoir evaluation. Porosity can determine the capacity and quality of reservoir for application of different recovery processes. Three different porosity values were selected to verify the effect of porosity on SAGD process, note that permeability values were kept fixed. Results illustrate that lower porosity causes a higher recovery factor while the amount of SOR is tremendously higher. The reason is that for a reservoir with lower porosity the initial oil in place is lower so lower amount of heat and energy is needed to heat up the reservoir. Therefore, the process in a lower porosity reservoir with a same steam injection rate and same period of injection becomes mature sooner but due to this lower porosity most of the injected heat will be lost due to the conduction to the reservoir rock. In general, reservoirs with higher porosity have better quality for SAGD process considering commercial and economic issues like SOR. Figure 14 represents results of the sensitivity analyses on porosity.

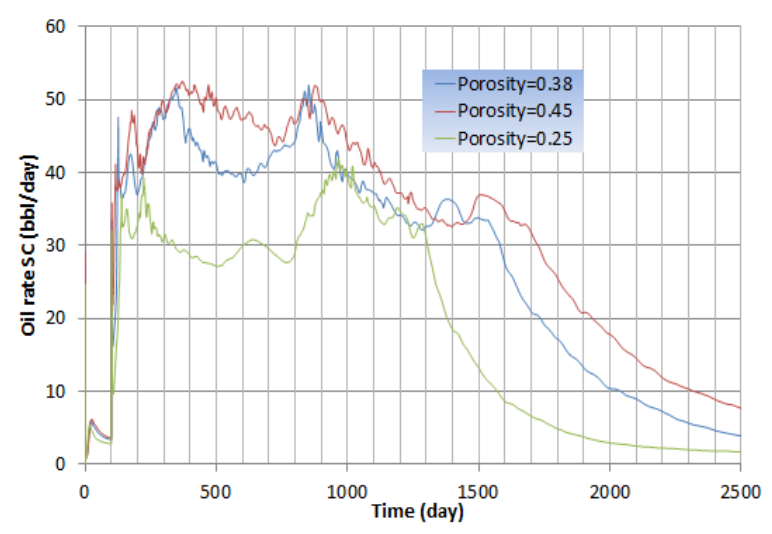

a) Oil rate vs. Time

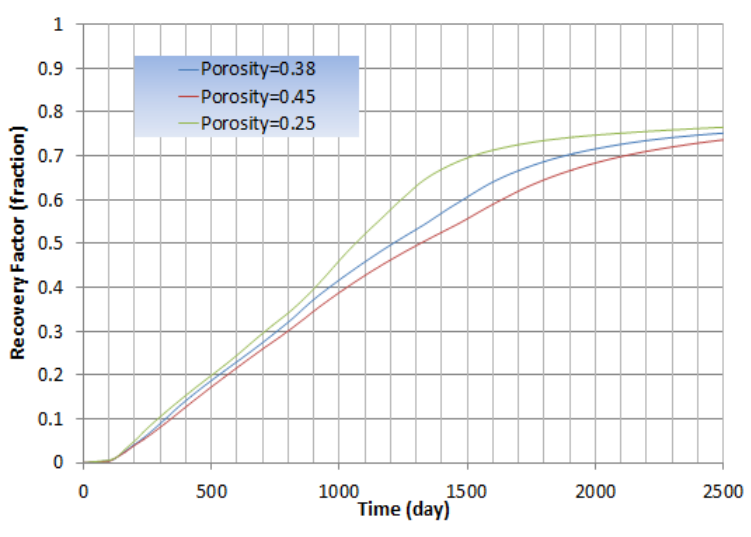

b) Recovery factor vs. Time

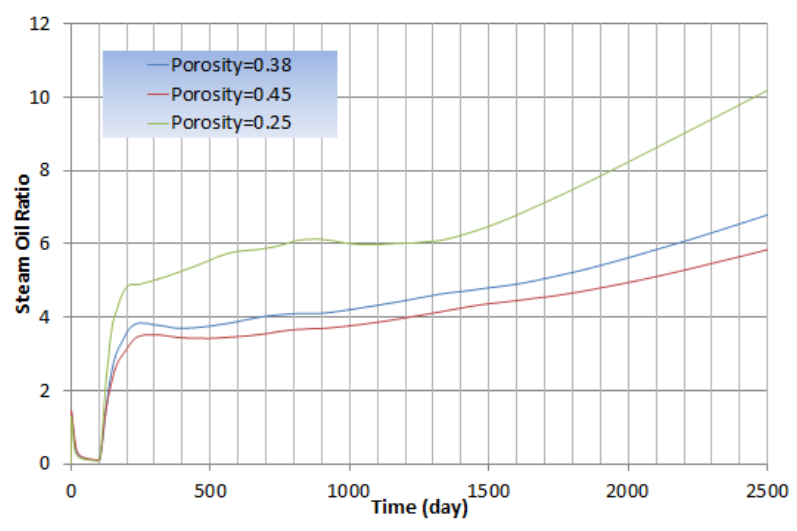

c) CSOR vs. Time

Figure 14. Representation of porosity effect on SAGD performance

\subsubsection{Effect of Injection Well Location}

Typically $5 \mathrm{~m}$ vertical spacingis considered between the horizontal injection well and the horizontal production well in the field conditions. Here, the aim is to study the effect of different injector locations on recovery performance. Therefore, the injector was located closer to the producer ( $2 \mathrm{~m}$ above). Figure 15 compares results of change in injector location and obviously it can be observed that higher amount of SOR will be obtained due to the production of steam (early steam breakthrough) when injector is located closer to producer. Also recovery factor would be lower because some of the injected steam is produced and is not helping in viscosity reduction of bitumen and growth of steam chamber. 


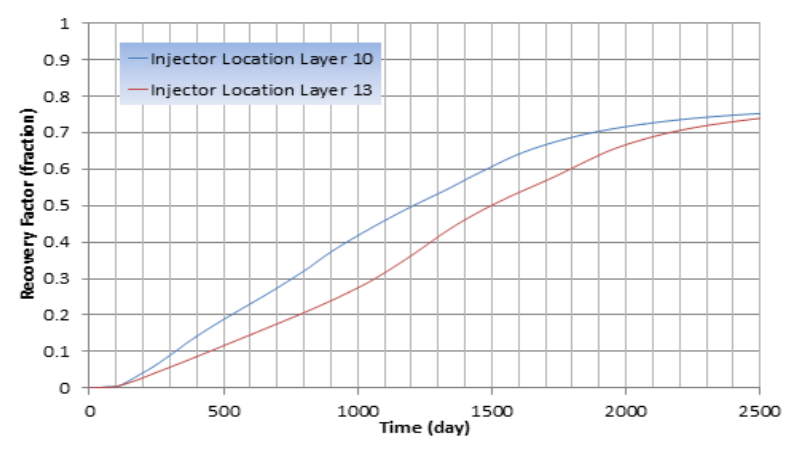

a) Recovery factor vs. Time

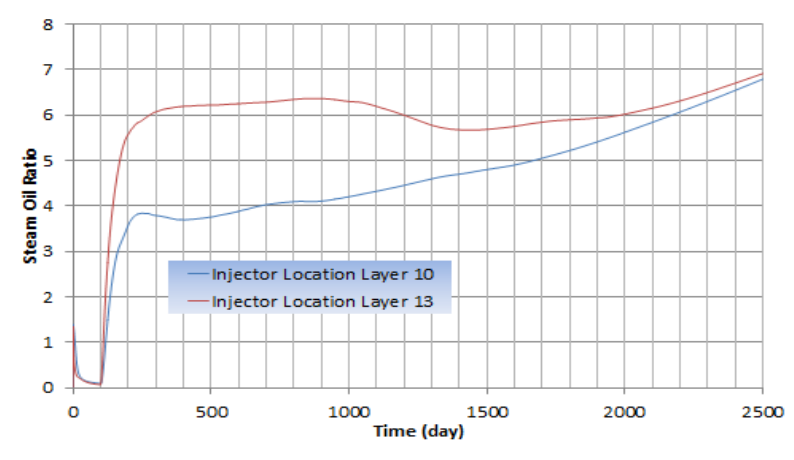

b) CSOR vs. Time

Figure 15. Illustration of horizontal injection well location effect on SAGD process

\subsubsection{Effect of Injection Rate}

Typically higher injection rate leads to higher injection of heat and energy through the reservoir and consequently earlier start of the production whereas higher amount of SOR may be resulted. Comparison of three different injection rates demonstrated that there is an optimum injection rate considering the recovery factor and SOR. Figure 16 shows effect of different injection rates.

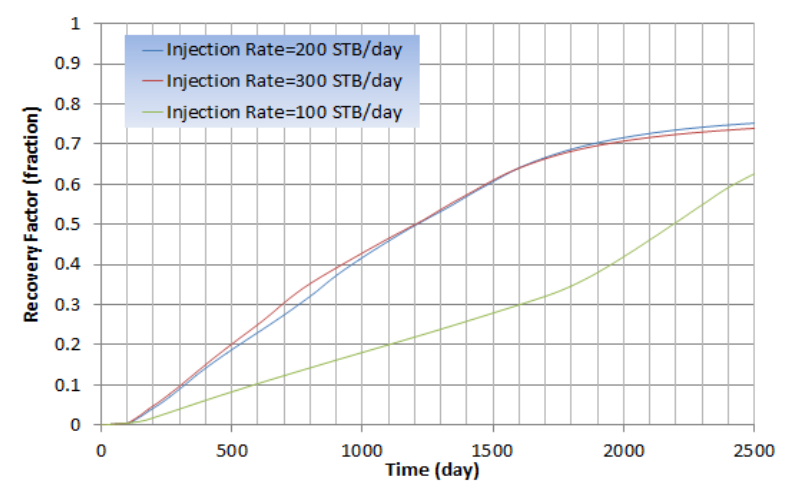

a) Recovery factor vs. Time

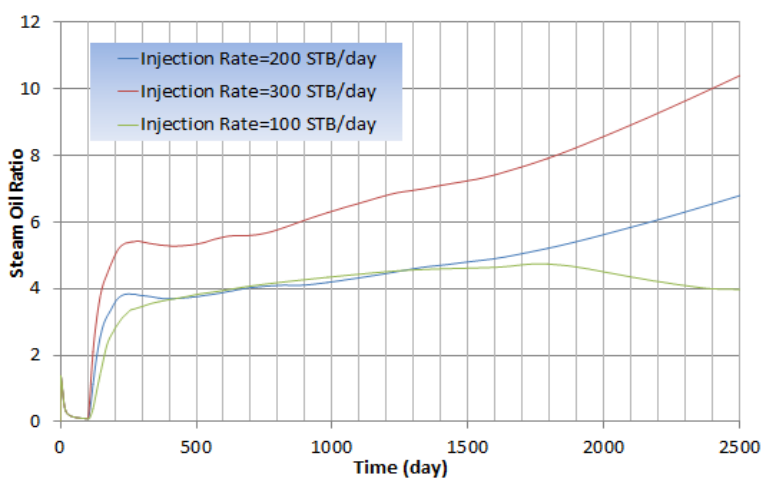

b) CSOR vs. Time

Figure 16. Illustration of different steam injection rates effects on SAGD performance

\subsubsection{Effect of Preheating Period}

Owing to the extra high amount of bitumen viscosity it is necessary to create a good communication between two horizontal wells in SAGD process. This phase is called preheating period. In this period the distance between two horizontal wells will be heated either by steam injection and circulation or by electrical heaters. The optimum of this period should be obtained because longer periods will result into later start of production whereas the communication between two wells may not be established successfully for shorter periods. Results are depicted in Figure 17. 


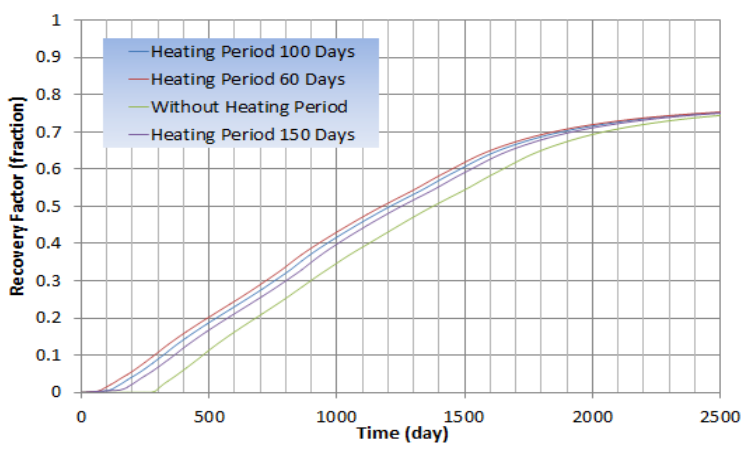

a) Recovery factor vs. Time

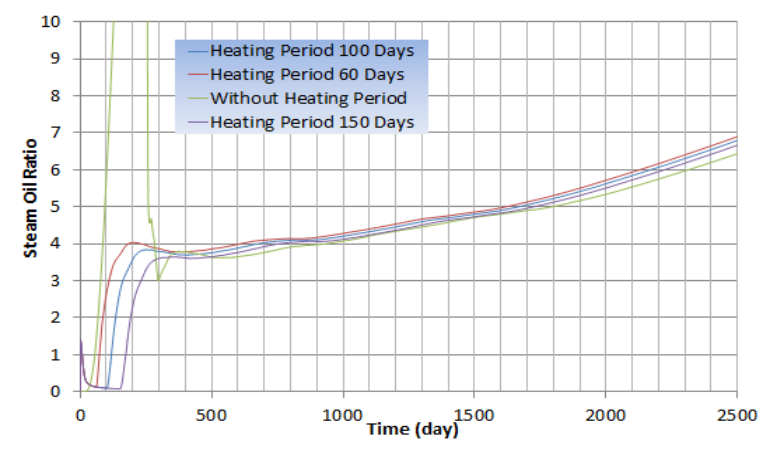

b) CSOR vs. Time

Figure 17. Illustration of preheating period necessity for SAGD process

\subsubsection{Effect of Steam Quality}

Steam has higher heat content than hot water due to the latent heat of steam. Consequently dry steam has the highest heat content and can inject more energy into the reservoir. However, due tosome operational difficulties such as corrosion of steam generator and high consumption of fuel for generation of steam, it is not possible to inject dry steam inside reservoir. Therefore, use of wet steam or steam plus hot water is more common in field conditions. Steam quality is defined as the mass fraction of vapor in the total stream. Here three different steam quality values were studied to investigate the optimum steam quality for injection. Results show that higher steam quality gives the greatest recovery factor and the lowest SOR (Figure 18).

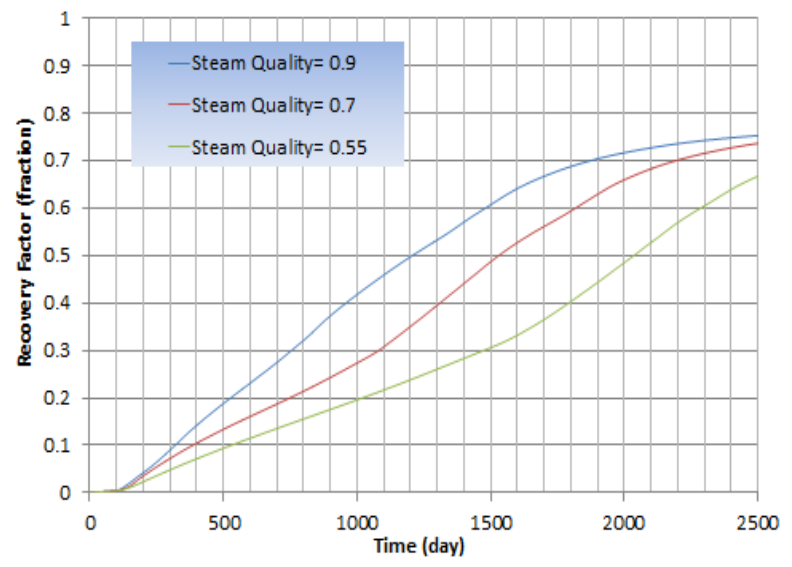

a) Recovery factor vs. Time

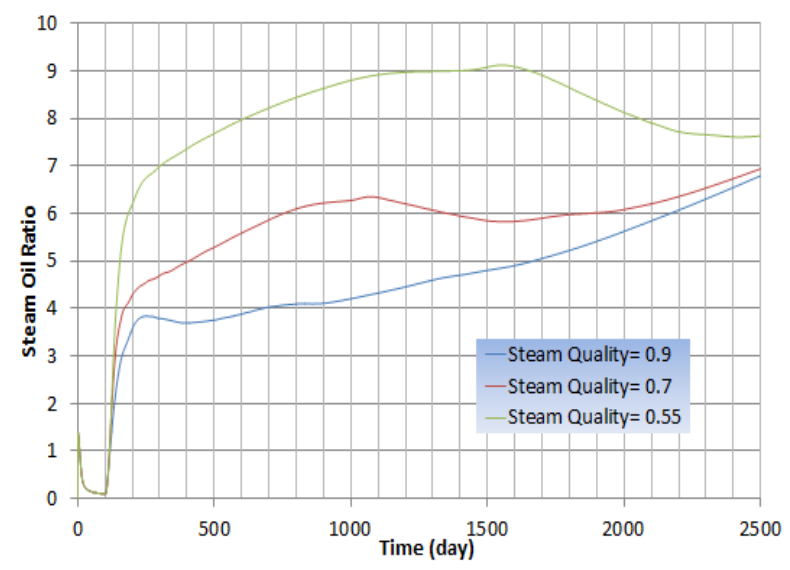

b) CSOR vs. Time

Figure 18. Illustration of steam quality effects on SAGD performance

\subsubsection{Effect of Shale Barrier}

Any barrier inside the reservoir formation can hinder propagation of the steam and consequently destroy the steam chamber growth. Barriers direction has an impact on hindering steam propagation. In order to evaluate the effects of shale barriers, sensitivity analyses were performed on horizontal and vertical shale barrier schemes (Figure 19). The comparison of these two schemes and the base case without any barriers are shown in Figure 20. As it can be seen, horizontal shale barriers have the worst effects because they can seal some parts of the reservoir and greatly hinder steam chamber growth. 


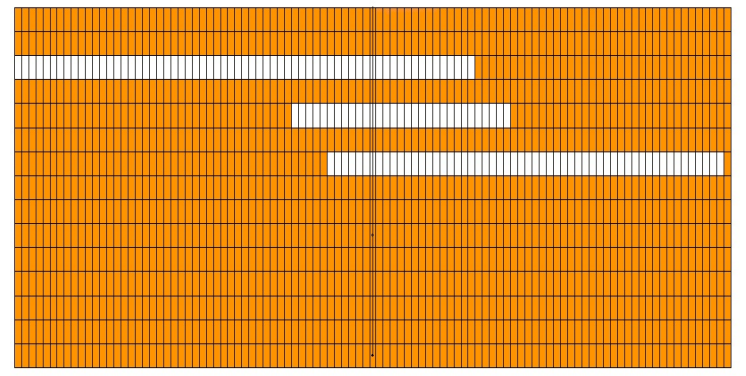

I) Horizontal shale barrier scheme

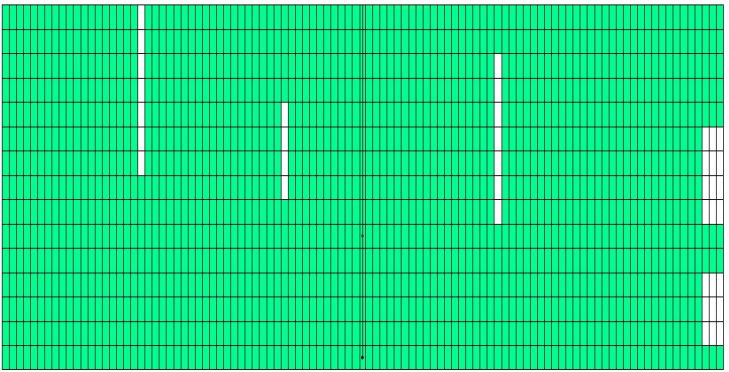

II) Vertical shale barrier scheme

Figure 19. Representation of different shale barrier schemes

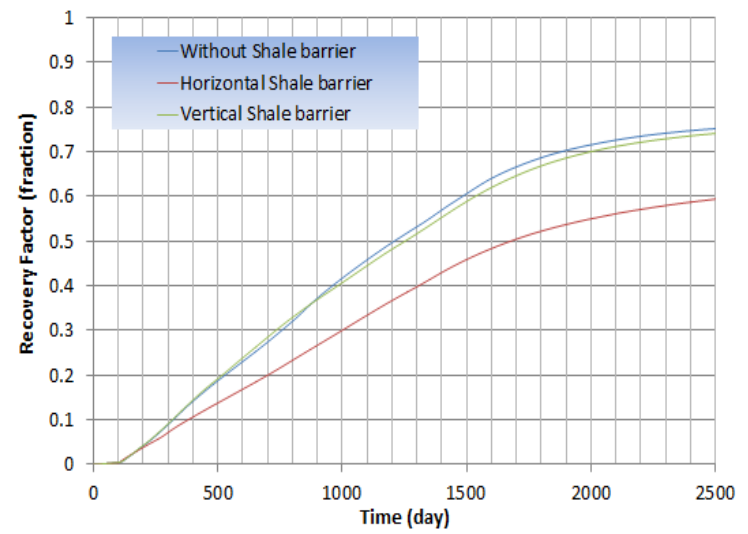

a) Recovery factor vs. Time

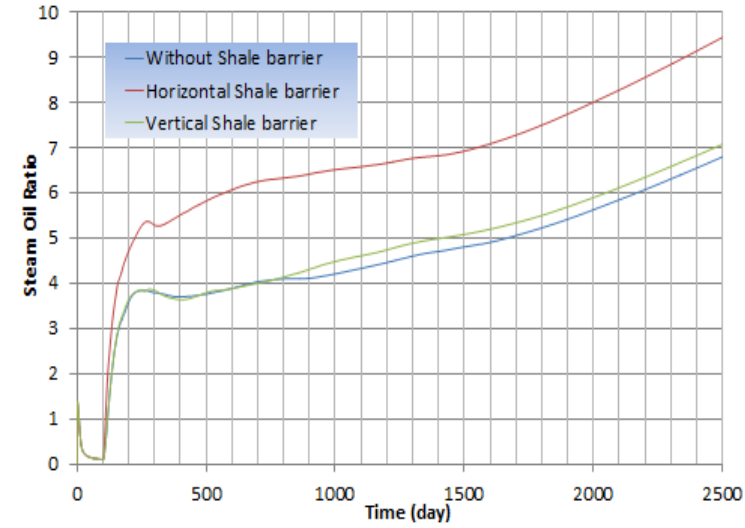

b) CSOR vs. Time

Figure 20. Illustration of shale barrier impacts on SAGD performance

\subsubsection{Effect of Horizontal Well Length}

Length of the horizontal wells has a great effect on production performance because the higher the horizontal well length the bigger the contact area. Note that drilling issues and difficulties should be considered also. Sensitivity analyses on two different scenarios illustrated that the amount of SOR would be greater for a shorter length due to the lower production of oil. Figure 21 demonstrates these findings.

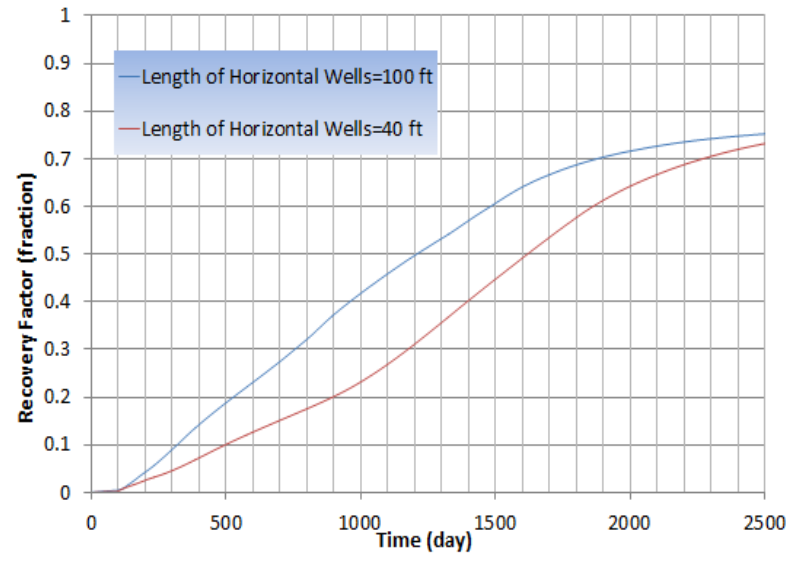

a) Recovery factor vs. Time

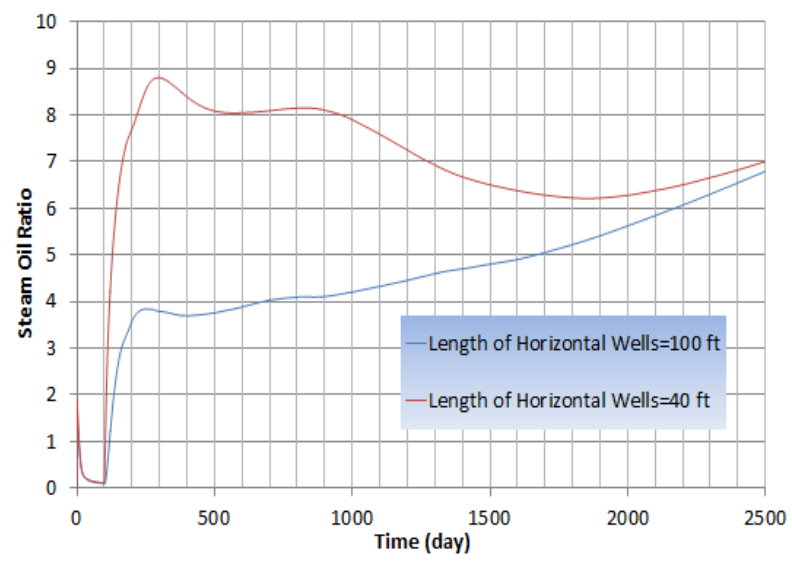

b) CSOR vs. Time

Figure 21. Illustration of horizontal well length effects on SAGD performance 


\section{Conclusion}

PVT properties of Athabasca crude oil were measured applying various experimental procedures. Gas chromatography was shown that there is no considerable concentration of hydrocarbon components lighter than $\mathrm{C}_{10}$ while due to facility limitation it was not practicable to determine components heavier than $\mathrm{C}_{38}$. Therefore hydrocarbon elements heavier than $\mathrm{C}_{38}$ were lumped in a group as $\mathrm{C}_{39+}$. The cryoscopy method was used to obtain the total molecular weight of the crude sample. The obtained value was $534 \mathrm{~g} / \mathrm{mole}$. Density of bitumen was measured at standard conditions by Anton Paar apparatus which was reported as $1.0129 \mathrm{~g} / \mathrm{cm}^{3}$. Beside the density of sample the density of $\mathrm{C}_{39+}$ fraction was obtained. The variation of sample density with respect to the changes in temperature and pressure were studied. An empirical correlation was presented based on experimental data within the studied range of temperature and pressure. It can be used to anticipate the Athabasca crude oil viscosity at different pressures and temperatures. The IFT values between steam and bitumen were measured for a range of temperature from $120^{\circ} \mathrm{C}$ to $220^{\circ} \mathrm{C}$. The great outstanding of this study was subtractive trend of IFT with respect to increase in temperature.

Results of numerical simulations show that SAGD is advantageous for production of bitumen by considering of recovery factor and CSOR. Effects of some properties were studied and following finding were obtained:

1) Higher viscosity will result in higher CSOR at earlier times

2) Permeability has tremendous effects on SAGD performance. For reservoirs with same permeability values, one which has lower porosity will show better recovery factor and concomitantly higher CSOR.

3) Location of injector closer than $5 \mathrm{~m}$ to the producer leads to higher CSOR and lower recovery

4) Optimum injection rate of steam should be obtained and evaluated for each reservoir

5) Preheating period is important for the start of the process because it is not feasible to inject the steam intothe reservoir when there is no good communication between two horizontal wells. The optimum period should be obtained also.

6) Horizontal shale barrier has greater dramatic effects than vertical.

7) Simulation results corroborated that higher steam quality has a better effects on SAGD performance though it is not possible to inject steam with a quality higher than certain amounts in the field conditions.

8) Gravity drainage is a basic recovery mechanism of SAGD process, so it is obviously clear that wells with larger length guarantee better oil production and consequently enhance the profitability of the project.

\section{Acknowledgment}

The authors would like to gratefully thank SINTEF Petroleum Research Center, especially Bard J.A. Bjorkvik for valuable help and comments during experimental part of this work. Also, the financial support from Statoil ASA is highly appreciated.

$\begin{array}{ll}\text { Nomenclature } & \\ \text { SAGD } & \text { Steam Assisted Gravity Drainage } \\ \text { CSOR } & \text { Gas chromatography analysis } \\ \mathrm{RF} & \text { Cumulative Steam-to-Oil Ratio }\left(\mathrm{m}^{3} / \mathrm{m}^{3}\right) \\ \mathrm{IFT} & \text { Recovery Factor } \\ \mu & \text { Interfacial Tension, } \mathrm{mN} / \mathrm{m} \\ \Delta \rho & \text { Dynamic viscosity, } \mathrm{cP} \\ \mathrm{T}_{\text {ref }} & \text { Density difference, } \mathrm{g} / \mathrm{cm}^{3} \\ \mathrm{P}_{\text {ref }} & \text { Reference temperature, }{ }^{\circ} \mathrm{C} \\ \mathrm{P} & \text { Reference }(\text { calibration }) \text { pressure, bara } \\ \mathrm{T} & \text { Pressure, bara } \\ \rho_{\text {oil }} & \text { Temperature, }{ }^{\circ} \mathrm{C} \\ & \text { Oil density, } \mathrm{g} / \mathrm{cm}^{3}\end{array}$




\section{References}

Ashrafi, M., Souraki, Y., Karimaie, H., \& Torsæter, O. (2011). Experimental PVT Property Analyses for Athabasca Bitumen. Paper CSUG/SPE 147064 presented at the Canadian Unconventional Resources Conference held in Calgary, Alberta, Canada, 15-17 November. http://dx.doi.org/10.2118/147064-MS

Attanasi, E. D., \& Meyer, R. F. (2007). Natural bitumen and extra-heavy oil, in 2007 Survey of Energy Resources, eds., J. Trinnaman and A. Clarke: World Energy Council, 119-143.

Butler, R. M. (1991b). Thermal Recovery of Oil and Bitumen. Department of Chemical and Petroleum Engineering, Prentice Hall, New Jersey, No 7, pp. 285-358.

Butler, R. M., \& Mcnab, G. S. (1981).Theoretical Studies on the Gravity Drainage of Heavy Oil during In-Situ Steam Heating. Canadian Journal of Chemical Engineering, 59(4), 455-460. http://dx.doi.org/10.1002/cjce.5450590407

Butler, R. M., \& Mokrys, I. J. (1991a). A New Process (VAPEX) for Recovering Heavy Oils Using Hot Water andHydrocarbon Vapor. Journal of Canadian Petroleum Technology, 30(1). http://dx.doi.org/10.2118/91-01-09

Chen, Q. (2006). Assessing and Improving Steam-Assisted Gravity Drainage: Reservoir Heterogeneities, Hydroulic Fractures and Mobility Control Foam, Dissertation for Doctor of Philosophy Degree, Stanford University, USA. Retrieved from http://pangea.stanford.edu/ERE/pdf/pereports/PhD/ChenQing09.pdf

Gates, I. D., \& Chakrabarty, N. (2006). Optimization of Steam-Assisted Gravity drainage (SAGD) in Ideal Mc. Murray Reservoir. Journal of Canadian Petroleum Technology, 45, 54-62. http://dx.doi.org/10.2118/06-09-05

Katz, D. L., \& Firoozabadi, A. (1978). Predicting Phase Behavior of Condensate/Crude-Oil Systems Using Methane Interaction Coefficients. Journal of Petroleum Technology, (November 1978) 1649-1655. Trans., AIME, 265. http://dx.doi.org/10.2118/6721-PA

Mehrotra, A. K., \& Svrcek, W. Y. (1986). Viscosity of compressed Athabasca bitumen. Canadian Journal of Chemical Engineering, 64, 844. http://dx.doi.org/10.1002/cjce.5450640520

Nasr, T. N., \& Ayodele, O. R. (2005). Thermal Techniques for the Recovery of Heavy Oil Bitumen. SPE 97488 presented at SPE International Improved Oil Conference in Asia Pacific Held in Kuala Lumpur, Malaysia, 5-6 December. http://dx.doi.org/10.2118/97488-MS

Nasr, T. N., \& Ayodele, O. R. (2006). New Hybrid Steam Solvent Process for the Recovery of Heavy Oil and Bitumen. Paper SPE presented at the Abu Dhabi International Petroleum Exhibition and Conference, Abu Dhabi, 5-8 November. http://dx.doi.org/10.2118/101717-MS

USGS. (2007). Heavy Oil and Natural Bitumen Resources in Geological Basins of the World. Retrieved from http://pubs.usgs.gov/of/2007/1084/OF2007-1084v1.pdf

Wagner, W., \& Pruss, A. (2002). The IAPWS formulation 1995 for the Thermodynamic Properties of Ordinary Water Substance for General and Scientific Use. Journal of Physical and Chemical Reference Data, 31(2), 387-535. http://dx.doi.org/10.1063/1.1461829 